\title{
The relationship of cutting force with hole quality in drilling process of AISI H13 steel
}

\author{
$\dot{I}_{\text {ssmail Tekaüt }}{ }^{1, *}$, Halil Demir ${ }^{2}$ and Ulvi Şeker ${ }^{3}$ \\ ${ }^{1}$ Gazi University, Vocational School of Technical Sciences, Ankara, Turkey \\ ${ }^{2}$ Karabük University, Faculty of Technology, Department of Manufacturing Engineering, Karabük, Turkey \\ ${ }^{3}$ Gazi University, Faculty of Technology, Department of Manufacturing Engineering, Ankara, Turkey
}

\begin{abstract}
The harmony of the drilling machine-cutting tool-work piece is very important for producing the machine part with the ideal dimensions. For this purpose in this study, the effect of cutting forces on hole quality (surface roughness, diameter deviation and circular deviation) was investigated by $14 \mathrm{~mm}$ diameter uncoated and (AlCrN monolayer) coated carbide drills for drilling AISI H13 hot work tool steel on vertical machining center. Four different cutting speeds $(60,75,90$ and $108 \mathrm{~m} / \mathrm{min})$ and three different feed rates $(0.15,0.20$ and $0.25 \mathrm{~mm} / \mathrm{rev})$ were used in the experiments. Cutting forces have been found to be effective in improving hole quality. Better hole quality has obtained with coated drills than uncoated drills in experiments. It has been observed that coated drills have the effect of improving the hole quality due to the operation with less cutting force and better chip evacuation.
\end{abstract}

\section{Introduction}

Drilling is very important in machining. Since a larger drilled hole than the desired dimension is cause to junk of the part or the small hole from desired dimension need to a second process as reaming. These processes lead to time lost and increased cost. Therefore, It is very important to produce holes in desired quality in one go. In studies in literature; It is emphasized that cutting force increases with increase of feed rate and decreases with increase of cutting speed in drilling process. They observed that magnitude of the cutting forces had a negative effect on hole quality. Literature review indicates that cutting parameters and accordingly cutting forces are important factors to hole quality in drilling process [1-11]. Therefore, İn this experimental study, AISI H13 steel is drilled at four cutting speeds $(60,75$, 90 and $108 \mathrm{~m} / \mathrm{min})$ and three feed rates $(0.15,0.20$ and $0.25 \mathrm{~mm} / \mathrm{rev}$ ) using uncoated and $\mathrm{AlCrN}$ coated solid carbide tools with $14 \mathrm{~mm}$ diameter. The relationship of cutting force with hole quality in drilling process of AISI H13 steel are investigated.

\section{Material and method}

The AISI H13 hot work tool with hardness of 90 HRB $(184 \mathrm{HB})$ was drilled $14 \mathrm{~mm}$ in diameter with uncoated and multilayer coated (AICrN monolayer) solid helical carbide drill. The drilling depth is $3 \mathrm{D}$ and the cutting parameters were determined by choosing a starting value in the range of the cutting parameters recommended for the drills selected in the manufacturer's catalog (KARCAN). The initial value of $60 \mathrm{~m} / \mathrm{min}$ was reproduced in accordance with the ISO standard for Standard Numbers (R10, R20 and R40), starting from the condition that at least four different cutting speeds should be selected for each cutting condition specified in the life test standards. Experiments were carried out on these conditions using four different cutting speeds $(60$, $75,90,108 \mathrm{~m} / \mathrm{min})$ and three different feeds $(0.15,0.20$ and $0.25 \mathrm{~mm} / \mathrm{rev}$ ). The specimens prepared to be $25 \mathrm{~mm}$ in outer diameter and $35 \mathrm{~mm}$ in hole length were drilled at Johnford VMC- 550 brand CNC vertical machining center in Gazi University Technical Education Faculty, Department of Mechanical Education. In the experiments, quartz crystal based Kistler 9272 type dynamometer and Kistler Type 5070 amplifier, which have the same measuring capacity of three shear force components (Fx, Fy, Fz) and momentum $(\mathrm{Mz})$ were used. Average surface roughness, gross deviation (within tolerances) and circularity deviation of the machined surfaces were measured in order to determine the quality of holes obtained from the experimental studies depending on the input parameters. A needle-tipped Mahr Perthometer M1 device with a portable surface roughness device was used to measure the average surface roughness $(\mathrm{Ra})$ values on the machined surfaces. DEA GLOBAL CLASSIC 07.10.07 three-dimensional coordinate measuring instrument was used in determining of diameter and circularity deviation values. For each sample, the deviation values were determined by taking the arithmetic mean of the values obtained in first measurement from 30 points below $2 \mathrm{~mm}$, in the second measurement from 30 points below $4 \mathrm{~mm}$, in the third measurement from 30 points below $6 \mathrm{~mm}$ below from the bottom of the part. Arithmetic averages of the

\footnotetext{
Corresponding author: ismailt@gazi.edu.tr
} 
values obtained by measuring the circularity 2, 4 and 6 $\mathrm{mm}$ below the surface of the part were calculated to obtain the circularity deviation values.

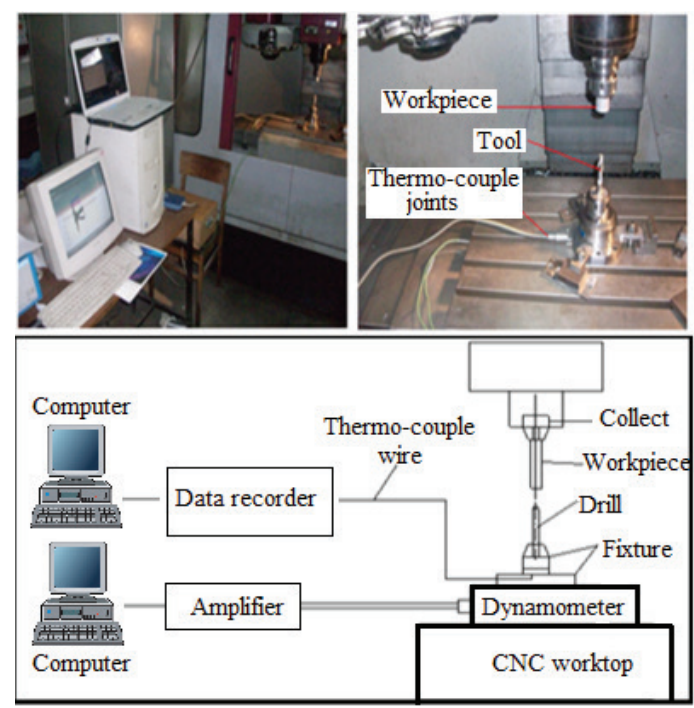

Fig. 1. Experimental setup

\section{Results and discussion}

The feed force, cutting force and moment values obtained by drilling the AISI H13 steel with uncoated and coated carbide drills at different feed rates and cutting speed combinations are plotted and shown in Fig. 2.

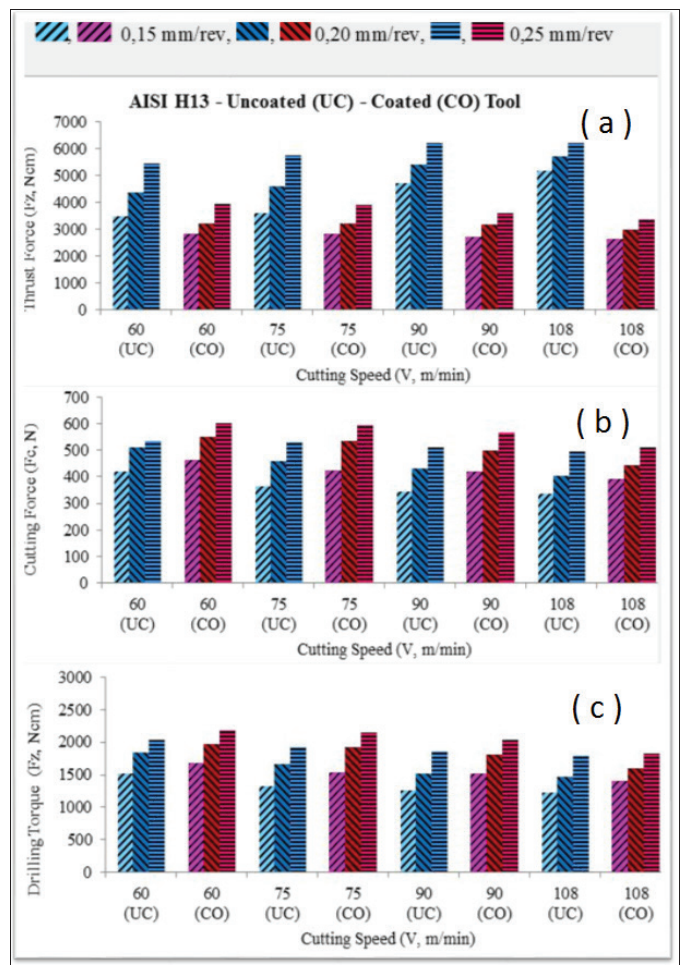

Fig. 2. Cutting forces depending on feed rate and cutting speed.

When examining of the graphs in Figure 2, both feed forces and moment values increased with increasing feed rate in all drilling experiments with uncoated and coated drills. This is attributed to the increase in the amount of advancement and the increase in the amount of drill cutting edges to increase the unit force in order to move faster along the perforation axis per unit of time and to raise the unit volume. Increasing chip volume with increasing feed rate caused the drill to use more cutting force to pull the increased chip volume from the material, resulting in larger moments generated by larger forces (Fig 2.a-Fig. 2.c).

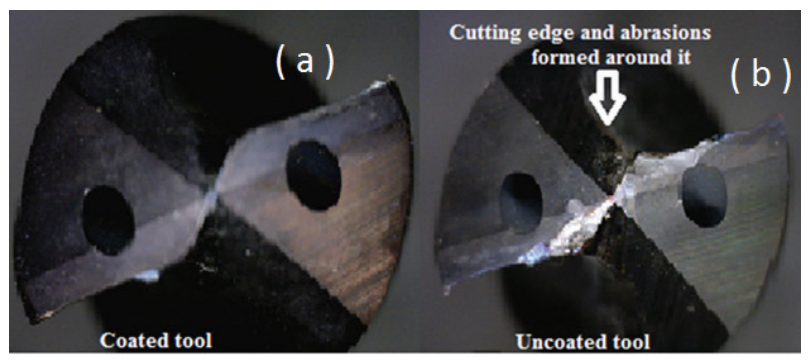

Fig. 3. Coated and uncoated drill

When the graphs are evaluated in terms of cutting speed, it was seen that the increase of the cutting speed in the drilling of the AISI H13 steel with uncoated drills caused to increase in the feed forces and decrease in the moment values. In drilling operations with veneer drills, the increase in cutting speed results in a decrease in both feed forces and moment values. In drilling operations with coated drills, the increase in cutting speed results in a decrease in both feed forces and moment values. This can be attributed to increased wear on the uncoated drills (see Figure 3.a) with increased cutting speed, and higher performance due to the coating material properties on coated drills. In processes with coated drills, increased temperature with increasing cutting speed [12, 13] caused to the deformation of the chip with less force and the facilitated chip evacuation led to a reduction in feed forces. The reduction in the feed forces and the cutting forces resulted in a reduction in moment values (see Figure 3.a - Figure 3.c). As the cutting speed increases, the cutting force and moment values decrease while the feed force increases in the case of uncoated drills. This situation can be explained by the increased wear in the end zone of uncoated drills (see Figure 3.b). Because of the increase in cutting speed, the wear on the drill has increased in the processes with uncoated drills. Due to the increased wear, the drill used more feed force to feed along the hole axis and caused to increase in this force. Increased wear with increased cutting speed made it difficult for the uncoated drill to feed along the hole axis and the drill's distance to the drill hole along the drill axis was further shortened. The shortening of the length that the drill was going to take at unit time has caused the reduction in the amount of chips to be removed. The reduction in chip volume caused a reduction in the cutting forces and so moments, as opposed to the feed forces. This is evidenced by the fact that in drilling with coated drills the decreasing feed force with decreasing cutting speed is less and less prone to decreasing than uncoated drills, while the cutting force obtained by 
operations with coated drills are higher than those obtained with uncoated drills.

The roughness values occurred on the hole surface after drilling the AISI H13 steel with uncoated and coated drills are shown in Fig. 4 by converting the deviations from diameter and circularity into graphs. When examining the graphs, the increase in feed rate in both drill types led to an increase in surface roughness. This situation can be attributed to the increase in the feed forces with the increase in the feed rate (see Figure 2). Increasing cutting forces had a negative effect on surface quality. When evaluating in terms of cutting speed, increase of the cutting speed improved the hole surface quality obtained in the processes with coated drills, while it causes the deterioration in hole surface quality of same conditions with uncoated drills. This can be explained by the fact that the increase in cutting speed accelerates the wear in uncoated drills, the high performance of the coated drill in the case of coated drills, and the low friction coefficient of the coating material. Increased cutting speed in the case of coated drills improves surface roughness, while in the case of uncoated drills, acceleration of the wear at the drill bit with increasing cutting speed was resulted in a rougher surface (Fig. 4.a). When Figure 4.b is examined, the deviation values of diameter increase with the increase of the feed rate in all experimental results. This can be explained by an increase in the chip volume with increasing the feed rate and so increase in the cutting forces. The increase in the cutting forces acting on drill with increasing feed rate caused in drill axis more deviation from the hole axis in the drilling process. In the case of both uncoated and coated drills, the increase of the cutting speed led to the increase of the deviation values. This can be explained by more deviation of the drill axis from the hole axis with the result of the increase of the machine-tool vibration with increasing cutting speed and. The deviations obtained from the uncoated drills are higher than those obtained with the drilled drills. This can be explained by increased wear in the uncoated drill bit area parallel to the cutting speed increase with reducing the centering feature of the drill (see Figure 2.b). The reduction of the centering property of the drill led to more deviation of drill axis from the hole axis with both the increasing feed force and the increased machine-tool vibration together with the cutting speed. Not losing the centering feature of coated drills (see Figure 3.a.), the quick release of chip and the production with lower cutting forces were resulted in a lower vibration amplitude. Therefore, lesser deviation values were recorded for coating drillings than uncoated drills.

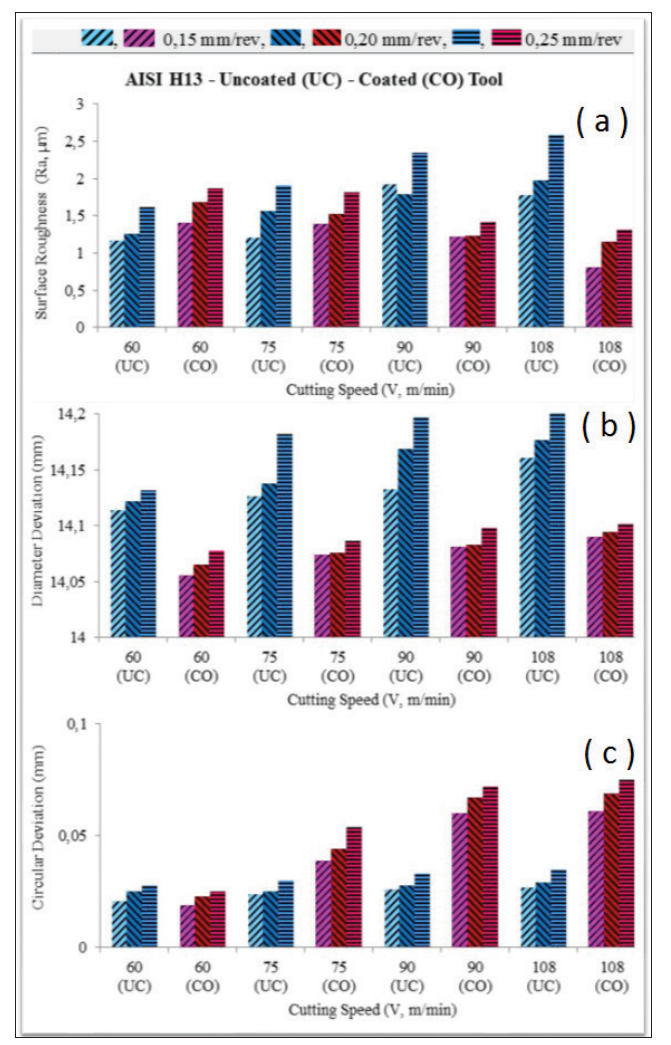

Fig.4. Cutting speed hole quality relations

In all experiments with uncoated and coated drills, the increase in the feed rate caused an increase in the deviations from the circularity. This can be attributed to increasing cutting forces as a result of the increasing feed rate. This is because the vibrations between the tool and the workpiece during drilling affect the drill bit and the higher cutting forces acting on the drill during the machining are more likely to cause the drill vibration amplitude to increase due to the effect of the tool-lathe vibration, causing the drill axis to move further away from the hole axis led to the increase in deviation from the circularity with the deviation of the diameter. The increase in shear rate in all test results led to an increase in deviation from circularity. As the drill rotation speed increases, the vibration amplitude of the system also increases and causes an increase in deviation from circularity. The fact that the deviations from circularity of holes obtained in uncoated drills are lower than that of coated drills can be explained by the fact that the cutting forces of coated drills (tangential force) are greater than that of uncoated drills (see Figure 3.a and Figure 3.c). The drill vibration amplitude has increased because the high tangential forces observed in the coated drills contribute to the drill-lathe vibration as a compelling force during chip removing.

\section{Conclusions}

The following results were obtained in the drilling process of AISI H13 steel with uncoated and (AlCrN monolayer) coated carbide drills. 
- The increase in the feed rate in all experiments led to an increase in cutting forces. This is attributed to the increased chip volume with increasing feed rate.

- Increase in cutting speed leads to an increase in the feed force in uncoated drills, which causes a decrease in cutting force and moment. This caused the drill bit to expand too much force to move along the hole axis in the result of wear on the drill bit together with the cutting speed. However, due to wear, the reduction of the chip volume removed by unit time caused to more decrease of cutting force and moment.

- The cutting speed increase has resulted in a reduction in cutting forces in all experiments with coated drills. This is attributed to the acceleration of the chip evacuation along with the increase of the cutting speed and to the deformation of the chip with less force.

- Increase in the feed rate led to increasing of surface roughness, deviations from the diameter and circularity. This condition is attributed to increasing cutting forces.

- Increase in cutting speed causes increase of roughness values in uncoated drills, but decrease in coated drills. This can be attributed to increased wear in uncoated drills, and to rapid chip removal in coated drills.

- The increase in cutting speed causes to increase in the deviation from both the diameter and circularity. This can be attributed to an increase in the lathe-tool vibration with increasing cutting speed.

- In drilling operations with uncoated tools, the deviation values from diameter are greater than those with drilled drills. This can be explained by the reduction of the centering feature of the drill due to the wear on the tip of the uncoated drill.

- The values of deviation from the circularity in the operations with the coated drills are higher than those of the uncoated drills. This can be explained by the increase in vibration amplitude of the drill.

\section{References}

1. D. Umbrello, S. Rizzuti, J.C. Outeiro, R. Shivpuri, R. M'Saoubi, J. of Mat. Processing Tech., 199 (2008)

2. M. Usta, Master Thesis, G.U. Institute of Science, Ankara, (2010)

3. O. İşbilir, E. Ghassemieha, Procedia Eng., 10 (2011)

4. E. İnçal, MSc Thesis, Y.T.Ü., İstanbul, (2007)

5. T. Kivak, U. Şeker, International Iron \& Steel Symp., Karabük, (2012)

6. A. Çakır, M. Nalbant, A. Duran, H.B.Ulaş, 3. National Chip Manuf. Int. Symp, Ankara, (2012)

7. N. Tosun, C. Özek, G.Tosun, 11. International Machine Design and Manuf. Cong., Antalya (2004)

8. İ. Özkul, B. Buldum, A. Akkurt, Pamukkale University, Journal of Engineering Sciences, 19 (2013)

9. T. Kıvak, A. Çiçek, Y. Turgut, İ. Uygur, E. Ekici, 6th Int. Advanced Techn. Symp. (IATS'11), Elazığ (2011)

10. G. Meral, M. Sarıkaya, H. Dilipak, Erciyes Üniversitesi Fen Bilimleri Enstitüsü Dergisi, 27 (2011)

11. A.D. Jayal, A.K. Balaji, R. Sesek, Journal of Mat. Pro. Techn. 9 (2007)

12. M.C. Çakır, Vipaş A.Ş., Bursa, (1999)

13. W.B. Palmer, P.L.B. Oxley, Proc. Inst. Mech. Engrs., 173 (1959) 